\title{
Televizyon Reklamları, Çocuk ve Tüketim: Tarz mısın, Değil misin?
}

\author{
Döndü BAL \\ Araştırma Görevlisi \\ Anadolu Üniversitesi İletişim Bilimleri Fakültesi \\ dondubal@anadolu.edu.tr \\ Orcid: 0000-0002-6019-3831
}

\section{Atılım Onay}

Doç. Dr.

Anadolu Üniversitesi Illetişim Bilimleri Fakültesi

aonay@anadolu.edu.tr

Orcid: 0000-0002-0086-3207

\begin{abstract}
TV Commercials, Child and Consumption: Are You Stylish or Not?

The meanings attributed to the objects of consumption begin to become more valuable than the objects themselves. The advertisers who are aware of this situation try to convey these meanings to people through various messages. This effort is also directed towards children. Children are exposed to concepts such as fashion, conspicuousness and superiority even at their early childhood periods. Besides, when children are encouraged to be like an adult with consumption objects, the situation becomes more crucial. In this research, qualitative research method was used; data were collected by semi-structured interviews. The data obtained from the interviews was analyzed by descriptive analysis method. In this study, the thoughts of children about fashion concept, opinions about clothing produced in adult style, their perception about the general purposes of advertisements, the meanings that they attribute to the consumption objects they see in advertising and the role of family on shopping preferences were examined. While a consensus was discovered in terms of
\end{abstract}


fashion, general aims of advertisements and the role of family on shopping preferences; there was a gender-based difference among children in terms of clothing produced in adult style, and meanings attributed to the consumption objects in the advertisement.

keywords: Television, advertising, child, fashion, and concumption

\section{Résumé}

\section{Les publicités télévisées, l'enfant et la consommation : Tu es stylé ou non ?}

De nos jours, la valeur des significations attribuées aux objets de consommation est beaucoup plus grande que la valeur réelle des objets euxmêmes. Les publicitaires, conscients de cette situation, essaient donc de transmettre ces significations aux gens, y compris les enfants. Dès leurs enfances, les enfants sont exposés à la mode, au fait d'attirer l'attention et au sentiment de supériorité. Lorsque cela s'ajoute à l'encouragement des enfants à devenir des adultes par l'intermédiaire des objets de consommation, la situation devient plus grave. Dans cette étude, une recherche qualitative fut menée; les données ont été recueillies par des entretiens semi-structurés dont les données ont été analysées par une méthode d'analyse descriptive. Les sujets traités sont: les réflexions des enfants sur la mode, sur le style adulte des vêtements qui leur sont consacrés; leurs perceptions à propos des objectifs des publicités; le sens qu'ils attribuent aux objets de consommation qu'ils voient dans les publicités et le rôle de la famille dans les préférences d'achat. Alors que les opinions sont plutôt communes sur la mode, les objectifs des publicités et le rôle de la famille dans les préférences d'achat, il a été constaté qu'il y a une différence fondée sur le sexe des enfants en ce qui concerne les vêtements du style adulte et les sens attribués aux objets de consommation vus dans la publicité.

mots clés: Télévision, publicité, enfant, mode et consummation

\section{Öz}

Günümüzde, tüketim nesnelerine yüklenen anlamlar nesnelerin kendisinden daha değerli bir hal almaya başlamıştır. Bu durumun farkında olan reklamcılar, çeşitli mesajlarla insanlara bu anlamları aktarmaya çalışmaktadır. Bu çaba çocuklara yönelik olarak da gerçekleştirilmektedir. Çocuklar, daha küçük yaşlarda moda, dikkat çekme, üstün olma gibi kavramlarla karşı karşıya bırakılmaktadır. Buna bir de çocukların tüketim nesneleriyle yetişkin bireylere özendirilmesi eklenince durum daha ciddi bir hal almaktadır. Bu çalışmada, nitel bir araştırma gerçekleştirilmiş; veriler yarı yapılandırılmış görüşme tekniğiyle 
elde edilmiştir. Görüşmelerden elde edilen veriler ise betimsel analiz yöntemiyle analiz edilmiştir. Çalışmada çocukların moda kavramına yönelik düşünceleri, yetişkin tarzında üretilen kıyafetlere yönelik görüşleri, reklamların genel amaçlarına yönelik algıları, reklamda gördükleri nesnelere yükledikleri anlamlar, alışveriş tercihlerinde ailenin rolü konuları incelenmiştir. Moda, reklamın genel amaçları ve ailenin alışveriş tercihlerindeki rolüne dair ortak görüşler elde edilirken yetişkin tarzında üretilen kıyafetler ve reklamda görülen tüketim nesnelerine yüklenen anlamlara ilişkin çocuklar arasında cinsiyete dayalı bir farklılığa rastlanmıştır.

Anahtar Kelimeler: Televizyon, reklam, çocuk, moda ve tüketim 


\section{Giriş}

“Görüleceksin. Fark edileceksin. Sergilediğin simgeler, en değerli varlıklarındır. Onlar seni kalabalıktan ayıracak. Birisi olacaksın 'seçilmiş grubaı katılmış olacaksın.» (Türkoğlu, 2000'den akt. Akpınar, 2015, s. 33).

Etrafımızın tüketim nesneleriyle çevrili olduğu, kitle iletişim araçlarında sürekli tüketimin özendirildiği bir dönemde yaşamaktayız. Bu dönemde kimliğin toplumsal oluşumunda, tüketim uygulamalarının önem kazandığı vurgulanmaktadır (Bocock, 1997). Bu durumun yansımalarının görüldüğü alanlardan biri de moda dünyasıdır. Kıyafetin artık, giyinme amacının ötesinde; statü, yaşam biçimi ve kendini ifade etme şekli olarak ortaya çıktığı görülmektedir. Modaya uyma durumunun ise kişiye ayrıcalıklı bir konum, bir imaj kazandıracağı düşünülmektedir (Akpınar, 2015). Bu koşulların yalnızca yetişkinler için mi geçerli olduğu yoksa çocukların da mı bu durumun içine çekildiği sorusu da ayrıca tartışılması gereken bir konu haline gelmiştir. Bu konunun tartışılmasında ise televizyon mecrası özellikle de bu mecradaki reklamlar kritik bir çıkış noktasıdır. Çünkü çocuk, televizyondaki reklamlardan, yalnızca reklamı yapılan ürünün bilgisini edinmez; aynı zamanda birtakım kültürel anlamları da edinir. Başka bir ifadeyle, reklamlar çocuklar için kültürel alana bakan bir penceredir (Moore-Shay, 1994). Çocuklar, bu pencereden ne giymesi, ne yemesi, ne içmesi gerektiğine dair ipuçları edinir; reklamları birer danışman olarak görür (Lawlor ve Prothero, 2008). Reklamdan öğrendikleri doğrultusunda, kendilerini tükettikleri ürünlerle sergileme çabası içerisine girer; tüketimle kendilerini daha güçlü hissederler (Chin, 2001'den akt. Ellis, 2011). Reklamdaki ürünü tüketmekle mutluluğu eşit sayar, reklamdaki ürünle kendilerini özdeşleştirirler. Dahası, bu ürünler büyüklerin kullandıklarının birer minyatürü şeklindeyse, kendilerini yetişkinler gibi giyinip, davranmaya yönlendirirler (Moore-Shay, 1994). Bu kritik tespitlerden hareketle bu çalışmada, çocukların moda kavramına dair düşünceleri, reklamların amacına dair algıları, yetişkin tarzında üretilen kıyafetlere yönelik görüşleri ve tüketim nesnelerine yükledikleri toplumsal anlamlar belirlenmeye çalışıımıştır.

\section{Çocuk, Tüketim ve Sosyalleşme}

Tüketim, belirli bir intiyacı gidermek için bir ürün ya da hizmetin elde edilmesi, kullanılması ve yok edilmesi süreci olarak tanımlanır (Odabaşı, 1999). Baudrillard, modern insanın hayatını ihtiyaçlarını sürekli yenileyerek geçirdiğini ileri sürer (2008). Diğer taraftan pazarlamacılar, bireylerin intiyaçlarını standartlaştırarak herkesin aynı marka ayakkabıyı giyme, aynı marka arabaya binme ihtiyacı hissetmesini hedeflenmektedir. Bu noktada tüketiciler, standartlaştırılmış ürünleri nasıl tüketeceklerini öğrenen birer öğrenci haline gelmiştir (Illich, 2011). Bu öğrenim sürecinde ise biyolojik intiyacı karşılayan ürünlerin yerini sosyolojik göstergeler almıştır (Baudrillard, 2008). Bir başka ifadeyle tüketim, geleneksel ihtiyaç giderme alanından öteye taşınmış, toplumdaki değerlerin de tüketilmesi durumu ortaya 
çıkmıştır (Orçan, 2008). Bahsedilen bu standartlaştırılmış ürünlerin ve ürünlerle ilişkilendirilen sosyolojik göstergelerin çocuklara da aşılanmaya başlaması, çocuk tüketim kültürü kavramının tartışılmasına zemin hazırlamıştır.

Çocuk tüketim kültürü, 20. yüzyılda $A B D$ 'de çocuk giyim endüstrisinin gelişmesiyle ön plana çıkmaya başlamış bir kavramdır. 1930'larda, reklamcıların, üreticilerin ve satıcıların çocukları doğrudan hedef kitle olarak görmeye başlamaları, bu kültüre odaklanılmasını sağlamıştır. 20. yüzyıın başlarından itibaren çocuklar kendi arzu ve istekleri olan bireyler olarak düşünülmeye başlanmıştır. Bu durumun bir sonucu olarak, tekstil üreticileri, çocukların ihtiyacının ötesinde onların hayal ettikleri tarzda kıyafetler tasarlamaya başlamıştır. 1930'lardan sonra, birçok markanın çocuk kıyafetlerini kendi aralarında yaş ve cinsiyete göre alt gruplara ayırdığı, mağazalarında ayrı çocuk kıyafet katları oluşturduğu görülmüştür. 1940'larda çocuklar için hazırlanan reklamlarda çocuklara bir şeylerin sahibi olmayı aşılayan ifadeler -ben, benim gibi- kullanılmaya başlanmıştır. 1950'lerde, tüketim ürünleri çocuklara televizyon aracılığıyla aktarılmaya başlanmıştır. 1940'larda ve 50'lerde çocuklar için moda kavramından da bahsedilir olmuştur. 1960'larda, çocuklar tüketici araştırmalarına dâhil edilmeye başlanmış; onların tüketim tercihleri ve fikirleri de akademik araştırmalara dâhil edilmiştir. 70'ler, çocuklar için özel olarak ürünlerin üretiminde patlamanın olduğu yıllar olmuştur. 80'lerde televizyonun yanında radyo, dergi ve gazetenin de çocuklar için tüketim içerikleri oluşturduğu görülmüştür. 90'larda, pazarlamacılar çocuk tüketicileri de kendi içlerinde alt segmentlere bölmeye başlamıştır. 1996'da ise ilk çocuk AVM'si 'Abbotts Kids Village' ABD'in Georgia eyaletinde açılımıştır (Ellis, 2011; Jacobson, 2008; Mc Neal, 1992). Görüldüğü üzere, çocukların tüketici olarak konumlandırılması uzun ve planlı bir süreç neticesinde gerçekleşmiştir.

Türkiye'deki çocuklarla ilgili istatistiki bilgiler, en son 2017 yılında TÜiK tarafından açıklanmıştır. Açıklanan rapordaki bazı bilgiler dikkat çekicidir (TÜiK, 2017): Türkiye'nin toplam nüfusu 80 milyon 810 bin 525'tir. Bu sayının 22 milyon 883 bin 288 'i çocuktur. Yani genel nüfus içerisindeki çocuk oranı \%28.3'tür. Çocukların genel nüfus içerisindeki oranının bu kadar yüksek olması, pazarlamacıların çocukları doğrudan tüketici olarak hedeflemelerine zemin hazırlamıştır. Bu durumun üç nedeni vardır: Çocukların artık harcama özgürlüğüne sahip olmaları, geleceğin tüketicileri olarak görülmeleri ve küçük yaşlarda markalarla tanışmalarının çocuklarda daha kolay marka sadakati yaratacağı fikridir (Ateşoğlu ve Türkkahraman, 2009). Bu gerekçeler, markaları, çocukları sosyalleşme süreçlerinde yakalamaya ve onları tüketime yönlendirmeye sürüklemiştir.

Sosyalleşme, kültürel norm ve değerlerin benimsenmesi, içselleştirilmesi, kültürel unsurların bireye aktarıması sürecidir. Çocuk toplum içerisinde zorunlu olarak bu sosyalleşme sürecine girmektedir (Ellis, 2011). Bu süreçte çocuk, yetişkinlerden aldığı bilgiyi arkadaş çevresine yaymakta, yetişkin kültürünün devamlılığına hizmet etmektedir (Corsaro, 2005). Çocukların tüketici olarak sosyalleşmesi ise çocukların tüketici olmak için sahip olmaları gereken bilgi, davranış ve yete- 
nekleri edinmeleri süreci olarak tanımlanabilir (Ateşoğlu ve Türkkahraman, 2009). Bu süreçte, özellikle grup psikolojisinin egemen olduğu dönemlerde, çocuklar kendi aralarında moda olarak tabir edilen tüketim ürünlerini gruptan dışlanmamak adına tüketme eğilimi göstermektedir (Doğan, 2003). Çünkü gelişim dönemlerinde akran baskısıyla karşı karşıya kalan çocularda, çoğu zaman akran baskısı ebeveyn baskısının önüne geçmektedir (Berger, 2000). Burada kız çocukları, çekiciliğe ve arkadaşları arasında kabul edilmeye oğlan çocuklarından daha fazla önem vermektedir (Özbek, 2002'den akt. Ateşoğlu ve Türkkahraman, 2009). Neticede, çocuğun zorunluluk olarak başlayan sosyalleşme süreci, gruptan dışlanmamak adına gerçekleştirilen gönüllü tüketim faaliyetleriyle devam etmektedir.

Çocukların tüketici olarak sosyalleşme süreçlerinde, reklamlar başat rol oynamaktadır. Bu süreçte, çocuğun reklama yönelik tepkileri üç aşamada gerçekleşir. Bunlar (Wisenblit vd., 2013):

1. Algısal Aşama: Çocuğun reklamları diğer TV programlarından ayırmaya başladığı, markaları ürün kategorileriyle çağrıştırmaya başladığı, basit tüketim senaryolarını anlamaya başladığı aşamadır. 3-7 yaş arası çocukların yaşadığı aşamadır.

2. Analitik Aşama: Reklamın ikna edici niyetinin çocuk tarafından algılanmaya başladığı dönemdir. Çocuk ürünle alakalı fonksiyonel bilgileri reklamdan edinmeye başlar ve satın alma niyeti geliştirir. 7-11 yaş arası çocukların yaşadığı aşamadır.

3. Yansıtma Aşaması: Reklamın asıl amacını anlayan çocuk reklama karşı şüpheci bir tutum geliştirmeye başlar. Karmaşık tüketim senaryolarını anlamaya başlar. Çocuğun satın almada yetkin hale gelmeye başladığı dönemdir. 11-16 yaş arası çocukların yaşadığı aşamadır.

Kısaca, tüketici olarak sosyalleşme sürecindeki çocuğun reklama karşı tepkileri, reklam farkındalığı ile başlamakta, satın alma niyeti ve reklama karşı şüphecilik ile devam etmektedir. Burada aile de başat bir rol üstlenmektedir. Çocuklar, ailelerini reklamı yapılan ürünü almaya teşvik etmeye ya da kendilerine o ürünü almalarını sağlayacak yeterli finansal desteği vermelerini sağlamaya çalışmaktadır (McNeal, 1992). Burada, çocukların reklamı yapılan üründen aileleri tarafından mahrum bırakılması durumunda, aile içi anlaşmazlıklar ortaya çıkarmakta ve çocuğun psikolojik gelişimini olumsuz etkilemektedir (Kuruoğlu, 1999'dan akt. Doğan, 2003). Bu konuda, reklamların çocuk tüketimi ve aile ilişkileri üzerinde olumsuz bir sürecin tetikleyicisi olabileceğine dikkat çekilmekte ve bu süreç şu şekilde anlatılmaktadır (Sağlam, 1990):

1. Reklamlara bağlı olarak çocukta ortaya çıkan tüketim isteği anne, baba ve çocuk ilişkilerinde zorluklar meydana getirmektedir,

2. Bu zorluklar finansal sorunları olan ailelerde çocuğun çoğu isteklerinin geri çevirilmesi noktasında en yüksek seviyeye ulaşmaktadır, 
3. Bu geri çevirme davranışı ailede suç duygusu yaratırken çocukta hayal kırıklığını beraberinde getirmektedir,

4. Ailede yaşanan bu uyumsuzluk, ailenin tüketim mallarına verdiği öncelik konusunda bir kararsızlık yaşamalarına neden olmaktadır.

Özetle, çocukta tüketim isteği yaratan reklamlar, bu isteğin maddi nedenlerden dolayı karşılanaması durumunda aile içi anlaşmazlıklara neden olmakta ve ailenin satın alma kararlarını sorgulmalarına yol açmaktadır.

\section{Televizyon Reklamları ve Çocuk Tüketiciler}

Reklam; ikna etme, hatılatma ve bilgilendirme gayelerine hizmet eden, kitle iletişim araçlarından faydalanan ve mesaj kontrolünün reklamı verende olduğu bir tutundurma çabası olarak tanımlanmaktadır (Altunışık vd., 2006). İnsanlar, bu tutundurma çabasında yer alan ürünün yanlızca işlevsel özellikleriyle ilgilenmez, aynı zamanda ürünün başkaları için neler ifade ettiğiyle de ilgilenir (Williamson, 2001). Bu durumun bir sonucu olarak da bastıramadıkları bir arzuyla kültür metalarını satın almaya ve kullanmaya çalışırlar (Adorno, 2009). Bu süreçte, meta pazarı yalnızca yetişkinleri hedef almaz, çocukların da bilinçaltlarına onlar farkında olmadan sızar (Ewen, 2001). New York Times'ta 1990 yılında yayınlanan bir makalede, çocukların da yetişkinler gibi, sahip olunan nesnelere giderek daha fazla önem vermeye başladığına; tıpkı yetişkinler gibi doğru marka ve nesneleri edinmeleri konusunda bir baskı ile karşılaştığına dikkat çekilmiştir (Berger, 2000). Burada, çocukların yaşamında önemli bir sosyalleşme aracı olan televizyon (Feshbach vd., 1979) ve televizyon reklamları çocuğa tüketim alışkanlıkları ve nesnelerinin tanıtılmasında büyük rol oynar (Tokgöz, 1982). Ne var ki, çocuklar bu tanıtma sürecinde oldukça savunmasızdır. Konuyla ilgili, Jacobson, John Locke'un çocuk zihnini "iyi ya da kötü birtakım bilgilerin işlenebileceği boş bir tahta" olarak tarif etmesini hatırlatır. Bu benzetme, onların yetişkinlerden daha kolay manipule edilebilir; istekleri ve arzuları daha kolay yönlendirilebilir olmalarına dikkat çekmektedir (Jacobson, 2008). Televizyondaki çocuk reklamlarının, ürünün rasyonel faydaları yerine hedonik faydalarını ön plana çıkarması, görsel ve işitsel unsurlar, animasyonlar, sihirli sahnelerle çekici hale getirilmesi çoğunlukla macera temelli bir düş dünyasındaki olayları sunması (Moore-Shay, 1994), bu manipüle ve yönlendirme sürecini kolaylaştırmaktadır. Neticede çocuklar, tüketim nesnelerini hayatlarının vazgeçilmezi haline getiren öznelere dönüştürülmektedir.

Televizyon reklamlarında sunulan mesajlar, çocuklara reklamdaki ürünü o an/zamanı geçmeden/hemen kullanmalarını tembihlemekte, bu şekilde onlara farklı olma duygusunu vadetmekte, bu mesajı alan çocuklarda da yeni olanın tüketilmesi ve kullanılması bir gereksinimmiş gibi bir algı oluşmaktadır (Tayfur, 1989'dan akt. Akpınar, 2015). 2003 yılında 114 çocuk ile yapılan bir anket çalışmasında, çocukların \%50'si TV reklamları olmadan alışveriş yapamayacağını dile getirmiştir. Yine aynı araştırmada yer alan anne ve babaların \%60.2'si, TV reklamlarının çocuklarının tüketim alışkanlıklarını değiştirdiğini düşünmektedir (Do- 
ğan, 2003). 2007yılında 4-13 yaş arası çocuğa sahip 105 aile ile gerçekleştirilen bir araştırmada, ailelerin \% 87.6'sı reklamların çocukları intiyaç dışı ürünleri almaya yönlendirdiğini, \%73.4'ü reklamların çocukları savurganlaştırdığını; \%66.7'si de reklamların çocuğun ahlaki gelişimine zarar verdiğini dile getirmiştir (Karaca, 2007). Görüldüğü üzere, çocuklar reklamlardan -daha özelde TV reklamlarındanciddi şekillerde etkilenmektedir.

\section{Çocuk ve Moda}

Moda kavramı Latince yapmak ve etmek anlamına gelen "factio ve facere" kelimelerine dayanır. Sonraları, "birilerinin yaptığı, şimdiki gibi olmayan/şimdikinden farklı, birinin giydiği şey" gibi anlamları ifade etmeye başlamıştır (Barnard, 2002). Günümüzde, daha çok kıyafet kavramıyla ilişkili olarak kullanıldığı görülmektedir. Yaşadığımız çağda, kıyafetler ve moda, çeşitli sosyal konularla ilgili -yaş, sosyal statü, cinsiyet, alt kültürel bağlar gibi- ayrımlar oluşturarak bu ayrımlara özgü bedenler yaratmaktadır (Entwhistle ve Wilson, 2001'den akt. Pilcher, 2011). Bu ayrımların farkında olan çocuklar, kıyafetleri kendi bedenlerini başkalarına sunmak için sembolik bir iletişim aracı olarak görmekte, modaya uygun ve trend kıyafetleri kimlik oluşturmak için önemsemektedir (Pilcher, 2011). Bu durum, çocuk modası pazarının oluşmasına ve önem kazanmasına zemin hazırlamıştır.

Çocuk modası pazarı, 1990'larda önemli bir sektör olarak ortaya çıkmıştır. 2000 'li yıllarda çocuk kıyafetlerinde markalaşma ön plana çıkmış, çocuk kıyafet pazarında ünlü moda tasarımcılarının imzası görülmeye başlamıştır. Bu dönemde, çocukların "modalanmış bedenleri" birer metafor, bir şeyleri göstermenin bir aracısı olmuş; çocuğun tercihleri, zevkleri ve kimliği moda tüketimi ile somutlaştırılmıştır (Crewe ve Collins, 2006). Pole ve arkadaşları, Cultures of Consumption Araştırma Programı kapsamında, moda giyinmenin çocuklar için yaş ilerledikçe daha önemli hale geldiği, 6 yaşındaki çocukların bile neyin cool neyin olmadığına dair farkındalık taşıdığı; son moda ve markalı kıyafetlerin çocuklar için sosyal kabul ve dışlanma açısından önemli olduğu sonuçlarına ulaşmıştır (2005). Tüm bu tespitler, moda kavramının çocuklar için önemli bir olgu olarak görüldügüne ışık tutmaktadır.

Son zamanlarda, çocuk ve moda konusuyla ilgili olarak yeni bir kavramdan söz edilmektedir: "Çocuk Kıyafetlerinin Yetişkinleştirilmesi" tarzda kıyafetlerin, çocuklar için replikalarının üretilmesi anlamına gelmektedir (Pole vd., 2005). Philippe Aries, çocukluk döneminin, çocukların yetişkin aktivitelerini anlamaya başladığı 5-7 yaş arasında başladığını belirtir. 7 yaşla beraber çocuklar aslında birer minyatür yetişkinler olarak görülmektedir (Postman, 1982'den akt. Weil, 2007). 8-12 yaş aralığına geldiklerinde, farklı ürünlerin özelliklerini kendi aralarında kıyaslamaya başlamakta; reklamda gördükleri ürünleri satın alma eğilimi göstermekte ve daha çok kendilerinden yaşça büyük bireylere hitap eden marka ve ürünlerin reklamlarını izlemek istemektedir (Kirsh, 2010). Başlangıçta,

1 The Adultification of Children's Clothing 
oyuncak talebinde bulunan çocuk, yaşı ilerledikçe ve reklamlara maruz kaldıkça kıyafet isteğine daha fazla yönelmekte, bir anlamda yetişkinlerin isteklerini ister hale gelmektedir (Moore-Shay, 1994). TV reklamlarının çocukları minyatür birer kadın ve erkek gibi sunması da bu istekleri körüklemekte; çoğu zaman onları, çocuk olduklarını unutma noktasına getirmektedir.

\section{Televizyon Reklamları, Çocuk ve Tüketim Araştırması}

\section{Araştırmanın Konusu ve Amacı}

Reklamların, çocukların tüketim ve moda algıları üzerinde etkili olup olmadığının konu edinildiği bu çalışmada, Türkiye'deki bir hazır giyim markasının çocuklara yönelik hazırladığı bir reklam filmi üzerinden çocukların moda, reklam ve tüketim olgularına bakışlarının ortaya çıkarııması amaçlanmıştır. Bu amaç doğrultusunda aşağıdaki araştırma sorularının yanıtları aranmaya çalışıııştır:

1.Çocukların moda kavramına dair düşünceleri nelerdir?

2. Çocukların TV reklamlarının amacına yönelik düşünceleri nelerdir?

3.Çocuklar, yetişkin tarzında üretilen çocuk kıyafetleri hakkında ne düşünmektedir?

4.Çocuklar, reklamlarda gördükleri tüketim nesnelerine hangi anlamları yüklemektedir?

5.Çocukların tüketim kararlarında ailelerin rolü nedir?

Bu sorulara yanıt bulmak için ise çocuklara şu görüşme soruları yönlendirilmiştir:

1. Günlük hayatında ne tarz kıyafetler giymeyi seversin?

2. Büyük abi/ablaların giydiği tarzda kıyafetler mi daha çok ilgini çeker yoksa çocuklar için hazırlanan süper kahramanlı kıyafetler mi? Neden?

3. Büyük abi/ablaların giydiği kıyafetlerin çocuklara göre olanlarının da yapılması hakkında ne düşünüyorsun? Sence neden böyle bir şey yapıyorlar? O tarz kıyafetler hakkında neler düşünüyorsun?

4. Sence moda ne demek? Çocuk modası hakkında neler düşünüyorsun? Çocukların modasını kim/ne belirler?

5. Sence reklamlar ne amaçla yapılıyor?

Reklam filmi izletilir, sorular devam eder.

6. Reklamdaki çocuğun sence nasıl bir hayatı var? Reklam çocukla ilgili nasıl bir hikâye anlatıyor sana? Mesela, yarın okula gittiğinde izlediğin reklamı arkadaşlarına nasıl anlatırsın?

7. Sence bu reklam, çocuklara, bu markanın kıyafetlerini giyerlerse arkadaşları arasında nasıl görünebileceklerini söylüyor? 
8. Sence reklamdaki çocuğun, arkadaşlarına göre daha ön planda olmasının nedenleri nelerdir?

9. Kendi sınıfında bir çocuk da reklamdaki çocuk gibi giyinse, sen ve arkadaşların ona nasıl bakardınız? Ne düşünürdünüz o çocukla ilgili?

10. Bu reklamdaki kıyafetleri beğensen ve almak isteseydin ama ailen alamayacağını söyleseydi nasıl tepki verirdin?

\section{Araştırmanın Önemi}

Araştırma, Türkçe literatürde kısıtlı çalışmaların olduğu, çocukların, reklam, moda ve tüketim temalarıyla ilgili detaylı görüşlerini sunması ve bu alandaki literatüre geniş bir bakış açısı kazandırması açısından önemlidir. Çalışmanın, bu konularda çocukları hedefleyecek reklam sektörü çalışanlarına da daha etik reklamlar geliştirmeleri adına kritik uyarılar taşıdığı düşünülmektedir.

\section{Araştırmanın Kapsamı ve Örneklem Kümesi}

Araştırma, Eskişehir ilinde yaşayan, çocukların ürünleri kendi aralarında kıyaslama yetisi kazandıkları; reklamı yapılan ürünü en çok satın alma eğilimi gösterdikleri ve kendilerinden daha büyük kişilere yönelik hazırlanan reklamları daha çok izleme eğiliminde oldukları, (Kirsh, 2010), 8-12 yaş aralığındaki 14 çocuğu ve onlara gösterilen kıyafet reklamına dair düşüncelerini kapsamaktadır. 8-12 yaş aralığı aynı zamanda, çocukların modanın aktif tüketicileri olarak görüldükleri yaş aralığıdır Bu yaş aralığındaki çocuklar için moda kıyafetler, kendi kimliklerini oluşturma ve sunma anlamı taşımaktadır (Pilcher, 2011). Nitel araştırmalarda, ideal bir örneklem büyüklüğü için temel kuralın, "bilgilerin doyuma ulaşması ile oluşan tekrarlama döngüsü" olduğu belirtilir. Doyum noktasında, her yeni örneklemin daha önceki örneklemden alınan verileri tekrarlaması söz konusudur (Morgan ve Morgan, 2008'den akt. Baltacı, 2018, s. 262). Araştırmada, doyum noktası 14. çocukta görülmüş; görüşmeler bu çocukta sonlandırılmıştır.

Araştırmanın örneklem kümesini, 8-12 yaş aralığındaki 14 çocuk oluşturmaktadır. Çocukların 7'si kız, 7'si oğlandır. Bu çocuklardan beşi 8 yaşında, dördü 10 yaşında, üçü 11 yaşında ve ikisi 12 yaşındadır. Katılımcıların belirlenmesinde olasılıklı olmayan örnekleme türlerinden kartopu örnekleme yönteminden faydalanılmıştır. Kartopu örneklem, öncelikli ulaşılan kişilerin önerilerinden yola çıkarak, ulaşılan kişi sayısının giderek çoğaltıldığı örnekleme türüdür (Yıldııım ve Şimşek, 2016).

\section{Seçilen Reklam Filmi Hakkında}

Araştırma, TV reklamlarının, çocuklara moda kavramını öğrettiği; onlara giydikleri kıyafetlerle arkadaş çevrelerinden farkılaşmayı vaad ettiği; onları yetişkin birer birey gibi giyinmeye ve davranmaya özendirdiği yargılarından yola çıkılarak gerçekleştirilmiştir. Bu amaçla, bir hazır giyim markası olan Koton'un Tarzı Olan 
Çocuklar reklam filmi (Koton, 2014) seçilmiştir. Reklam filminde, doğduğu andan itibaren çevresindeki çocuklardan farklı olmaya çalışan bir oğlan çocuğuna yer verilmektedir. Çocuk giydiği kıyafetler ile arkadaşlarından farklılaşmakta; tüm dikkatleri üzerlerinde toplamakta, arkadaş grubu içerisinde tarz ve cool görünmektedir. Yetişkin tarzda, lüks ve moda olarak tabir edilen kıyafetler çocuğun bedeninde sergilenmekte; çocuk bu kıyafetlerle yetişkinler gibi davranmakta ve kendini üstün olarak sergileyen tavırlarda bulunmaktadır. Reklamda ayrıca, oğlan çocuğunun tarzına benzer şekilde giyinen ve davranan kız çocuklarına da yer verilmekte; bu kız çocuklarının da diğer kız çocuklarından üstün ve farklı olduğunu gösteren bakış ve hereketlere yer verilmektedir.

\section{Veri Analizi}

Araştırmada, nitel araştırma yaklaşımı benimsenmiştir. Nitel araştırma "gözlem, görüşme ve doküman analizi gibi nitel veri toplama yöntemlerinin kullanıldığı, algıların ve olayların doğal ortamda gerçekçi ve bütüncül bir biçimde ortaya konmasına yönelik nitel bir sürecin izlendiği araştırma" şeklinde tanımlanır (Yıldırım ve Şimşek, 2016, s. 41). Çocukların düşünce ve algılarına dair detaylı veri elde edilmesi amacıyla, derinlemesine görüşme tekniğinden faydalanılmıştır. Derinlemesine görüşme tekniği, bir reklamın izleyici için ne ifade ettiğini ve izleyicinin bir reklamdan hangi anlamları çıkardığını ortaya koyabilen bir yöntemdir (Belk, 2017). Görüşme tekniklerinden ise yarı-yapılandırılmış görüşmeden faydalanılmıştır; çünkü yarı yapılandırımış görüşmeler, araştırmacıya beklenmedik yanıtlara karşı yeni görüşme soruları ekleme imkanı sağlar (Fox vd., 2018).

Çalışmada verilerin analiz edilmesinde betimsel analiz yönteminden faydalanılmıştır. Betimsel analizde, verilerin daha önceden belirlenmiş temalara göre özetlenmesi ve yorumlanması söz konusudur. Veriler, araştırma sorularıyla belirtilen temalara göre düzenlenebilir ya da görüşme sürecinde kullanılan boyutlar ve sorular dikkate alınarak da ortaya koyulabilir. Bu analiz türünde, görüşülen bireylerin fikirlerinin çarpıcı şekilde sunulması için sık sık doğrudan alıntılara yer verilir (Yıldırım ve Şimşek, 2016).

TV reklam filmi önce çocuklara kendi evlerinde, tek tek izletilmiş; ardından reklam filmi üzerine sorular sorularak çocukların cevapları, ailelerin ve çocukların izniyle ses kaydına alınmıştır. Veli izni konusunda, 10 çocuğun ailesinden yazıı veli onay formu imzası alınmış; forma imza atmak istemeyen 4 velinin de sözlü izni alındıktan sonra görüşmeler gerçekleştirilmiştir. Görüşmeler 5-23 dakika arasında sürmüştür. Ses kayıtları önce deşifre edilmiş, ardından belirli temalar şeklinde kodlanmıştır. Deşifre ve temalar çıkarma/ kodlama süreci, veriyi yönetilebilir küçük parçalar haline getirmek için gerçekleştirilen işlemdir (Ellis, 2011) Bu sürecin sonunda beş farklı tema belirlenmiştir. Bunlar: Moda kavramına dair düşünceler, TV reklamlarının amacına dair düşünceler, yetişkinlerin tarzında üretilen çocuk kıyafetlerine yönelik düşünceler, reklamdaki tüketim nesnelerine yüklenen anlamlar ve çocukların gözünde tüketim tercihinde ailelerin rolü'dür. 
Araştırmanın geçerlilik ve güvenilirliğinin sağlanması amacıyla hazırlanan sorular nitel çalışmalar gerçekleştiren iki araştırmacı ile paylaşılmış, onaylarının ardından görüşmeler gerçekleştirilmiştir. Deşifre sürecinin ardından belirlenen temalar, başka bir araştırmacı ile gözden geçirilmiş; üzerinde uzlaşılan görüşlere araştırmada yer verilmiştir. Bu sayede araştırmanın teyit edilebilirliği sağlanmıştır.

Araştırmada görüşmeciler ve cinsiyetlerine dair kodlamalar gerçekleştirilmiştir. İlgili kodlamalar ve katıımcı özellikleri aşağıdaki tablodaki gibidir.

Tablo 1. Kodlamalar ve katıımcı özellikleri

\begin{tabular}{|c|c|c|c|}
\hline Katılımcı 1 & G1 & 10 yaşında & Oğlan (O) \\
\hline Katılımcı 2 & $\mathrm{G} 2$ & 8 yaşında & Oğlan (O) \\
\hline Katılımcı 3 & G3 & 12 yaşında & $\mathrm{K} I \mathrm{Z}(\mathrm{K})$ \\
\hline Katılımcı 4 & G4 & 8 yaşında & Oğlan (O) \\
\hline Katılımcı 5 & G5 & 11 yaşında & Oğlan (O) \\
\hline Katılımcı 6 & G6 & 10 yaşında & $\mathrm{K} I \mathrm{Z}(\mathrm{K})$ \\
\hline Katılımcı 7 & G7 & 11 yaşında & $\mathrm{K} I \mathrm{Z}(\mathrm{K})$ \\
\hline Katılımcı 8 & G8 & 8 yaşında & $\mathrm{K} I \mathrm{Z}(\mathrm{K})$ \\
\hline Katılımcı 9 & G9 & 8 yaşında & $\mathrm{K} I \mathrm{Z}(\mathrm{K})$ \\
\hline Katılımcı 10 & $\mathrm{G} 10$ & 10 yaşında & $\mathrm{K} \mathrm{IZ}(\mathrm{K})$ \\
\hline Katılımcı 11 & $\mathrm{G} 11$ & 12 yaşında & Oğlan (O) \\
\hline Katılımcı 12 & $\mathrm{G} 12$ & 11 yaşında & Oğlan (O) \\
\hline Katılımcı 13 & $\mathrm{G} 13$ & 8 yaşında & $\mathrm{K} I \mathrm{Z}(\mathrm{K})$ \\
\hline Katılımcı 14 & G14 & 10 yaşında & Oğlan (O) \\
\hline
\end{tabular}

\section{Araştırmanın Bulguları}

Çalışmanın bu kısmında yukarıda değinilen temalara dair bulgular sunulmuştur.

\section{Moda Kavramına Dair Düșünceler}

Çocuklar moda kavramını; yeni, farklı, orjinal, lüks, herkesin istediği, o döneme uygun olan kavramlarıyla anlamlandırmakta ve açıklamaktadır. Konu hakkında aşağıdaki ifadeler dikkat çekicidir:

G12. Moda, yeni çıkan şeyleri alıp giymek demek. (O, 11 Yaş)

G14. Modayı diğer elbiselerden farklı olursa anlarım. (O, 10 Yaş)

G4. Moda, kıyafetlerin orjinal olması... (O, 8 Yaş) 
G2. Moda, daha lüks demek. (O, 8 Yaş)

G7. Moda, o aya, o haftaya uygun olan yani daha o haftaya tarz olan... (K, 11 Yaş)

G5. Moda insanların kıyafetlerini giydiği, herkesin istediği demek... (O, 11 Yaş)

Çocuklar, çocuk modası diye bir şeyin olabileceğini düşünmektedir. Çocuk modasını; yeni, tarz, çocuk olma haline uygun, kendi tercihine göre seçilmiş, renkli, ışıltılı ve süper kahramanlı kavramlarıyla ilişkilendirmektedir. Çocuk modasının, çocukluğu yansıtan özellikler taşıması gerektiğini düşünmektedir. Bu konuya oğlanların kızlardan daha fazla önem verdiği görülmektedir. Konu hakkında aşağıdaki ifadeler dikkat çekicidir:

G10. Çocuk modası da olur, yeni moda gelmiş yeni yeni kıyafetler gelmiş mağazalara diye öyle giyerler o çocuk modası olur... (K, 10 Yaş) G5. Çocuk modası, çocukların giydiği, nasıl diyim tarz giyinmek... (O, 11 Yaş)

G4. Çocuk modası çocuklara uygun güzel şeyler demek... (O, 8 Yaş) G1. Çocukların da modası olur. Çocuk kendi sevdiğini giyiyorsa bu bir modadır. (O, 10 Yaş)

G11. ... çocukların da modası olur ama onlar renkli, ışıklı mışıklı, ejderhalı falan olur... (O, 12 Yaş)

Kızların modayı ve dış görünüşlerini oğlanlardan daha fazla önemsediği ve modayı güzel olmakla iliş̧kilendirdiği görülmektedir. Araştırmadaki kız çocuklarına göre, özel günlerde modaya uygun giyinmek ve arkadaşları tarafından beğenilmek çok önemlidir. Ayrıca, başkalarının dikkatini çekecek kıyafetleri giymeyi önemsemekte ve kıyafetleriyle ön plana çıkma isteği taşımaktalar. Bu tespite dair aşağıdaki ifadeler dikkat çekicidir:

G10. Benim için modaya uygun giyinmek özel günlerde gerekli olabiliyor. Arkadaşlarımdan bazıları çok önemser modayı bazıları önemsemez, ben de modayı önemserim. (K, 10 Yaş)

G6. Modası geçmiş bişey giydim diyelim, insanların beğenmediğini düşünürüm, modayla alakalı şeyler giyerim... (K, 10 Yaş)

G6. Kıyafetin başkalarının dikkatini çekmesi benim için önemli. (K, 10 Yaş)

G9. Moda güzel olmak demek. Bize uygun demek, bize çok yakışır demek, çok güzel olmak demek..... Ben de öyle olmak isterim odalı elbiseyle... (K, 8 Yaş)

Çocuklar, modanın tasarımcılar tarafından yaratıdığını belirttiklerine göre, moda tasarımcısı kavramını bildikleri açıkça ortadadır. Üstelik, ünlü kişilerin giydiği kıyafetlerin ve sosyal medyanın modayı yarattığını düşünmeleri, hemen hepsinin 
(G5 ve G14 hariç) «moda» olanın reklamlardan öğrenildiği noktasında görüş birleşmesi, moda kavramına ne kadar hâkim olduklarının birer göstergesi niteliğindedir. Çocuklar, modanın nasıl yaratılığına yönelik sorulara şöyle cevaplar vermiştir:

G3. Moda tasarımcıları modayı yapar, etraftan görüşlerle kendileri planlayıp yapıyorlar. Bizler de reklamlardan biliyoruz o modayı... (K, 12 Yaş)

G11. Moda bir kişinin tasarladığı kıyafet reklamlarda çıkıyor sonra moda oluyor sonra da herkes giyiyor, kullanıyor onu. (O, 12 Yaş)

G1. Moda, ünlü biri bişey giyiyor, herkes vay anasına ben de giymeliyim diyor, moda budur bence. ... Sosyal medyada çok görüyorum bunu ünlü biri giymiş, çocuk da gidip aynı marka, aynısını almak istiyor. $(0,10$ Yaş)

\section{TV Reklamlarının Amacına Dair Düşünceler}

Görüşülen çocukların reklamların genel amaçlarından haberdar olduğu görülmektedir. Reklamların; ürünleri tanıtmak, onlar hakkında bilgiler vermek, ürünleri sattırmak, insanların ilgisini çekmek, insanları ürünlerden haberdar etmek amaçlarıyla yapıldığını düşünmektedirler. Bu konudaki ifadeler şöyledir:

G9. Reklamlar güzel elbiseleri tanıtmak için yapılıyor... (K, 8 Yaş)

G8. Reklamlar diyelim ki bir telefon, telefonun daha iyi, daha kaliteli olduğunu göstermek için yapılıyor. (K, 8 Yaş)

G10. Reklamlar orda ne olduğunu, ne kadara olduğunu göstermek için yapılıyor. Parasını, kıyafetleri, malzemeleri göstermek için yapılır. (K, 10 Yaş)

G14. Reklamlar, ordaki şeyleri çabuk almamız için, para kazanmak için yapıyorlar. (O, 10 Yaş)

Reklamların amacıyla bağlantılı olarak, reklamda tanıılan ürünleri satın alma isteği konusunda; kızların, oğlanlardan daha fazla satın alma isteği taşıdığı görülmektedir. Bu duruma, kız çocuklarının relamdaki ürünlerin insanların ilgisini çekeceği inancı neden olmaktadır. Konuya dair aşağıdaki ifadeler dikkat çekicidir:

G3. TV'deki kıyafet reklamlarından etkilenirim, alıım da o kıyafeti. (K, 12 Yaş)

G7. Reklamlarda bazı kıyafetler çok ilgi çekici olabiliyorlar, almak istiyorum reklamda gördüğüm kıyafetleri... (K, 11 Yaş)

G6. Reklamda işte gösteriyor böyle bir kıyafet var diye, beni haberdar ediyor, beni etkiliyor, özellikle şarkılı falan reklamlar beni çok etkiliyor. (K, 10 Yaş)

Kız çocuklarının bu eğiliminin aksine oğlan çocuklarının, reklamların amaçları konusunda daha bilinçli olduğu ve reklamlara karşı güvensizlik taşıdığı görülmektedir. Özellikle reklamda gösterilen ürünleri almak için mağazalara gittik- 
lerinde, reklamdaki ürünle mağazadaki ürünün aynı çıkmadığı yönünde bir algı taşımaktadırlar. Bu tespitle ilgili aşağıdaki ifadeler dikkat çekicidir:

G4. TV reklamlarındaki kıyafetler beni etkilemiyor, çünkü almaya gidince mağazada aynısını göremiyorsun. Reklama güvenmem ben. (O, 8 Yaş)

G5. Reklamlar, o mağazanın ürünlerini tanıtmak için yapılır ama giyecek reklamları bana fayda sağlamıyor, Tv'den bi reklam izliyorum, gidiyorum o mağazaya o şeyleri (ürünleri) orda göremiyorum. $(\mathrm{O}, 11$ Yaş)

\section{Yetişkinlerin Tarzında Üretilen Çocuk Kıyafetlerine Yönelik Düşünceler}

Oğlanlar, çocukların çocuk gibi giyinmesi gerektiğini, yetişkinlerin tarzında üretilen kıyafetleri beğenmediklerini, bu tarz kıyafetlerin havalı olmak, ilgi çekmek adına tercih edilse bile aslında çocuklar için uygun olmadığını dile getirmektedir. Bu noktada, oğlan çocuklarının yaş ve kıyafet tercihinin uyumu konusunda daha bilinçli olduğu söylenebilir. Konuyla ilgili aşağıdaki ifadeler dikkat çekicidir:

G11. Bizim sınıfta kızlar böyle tayt gibi kotlar giyiyorlar hiç sevmiyorum. Hocalar "Sen liseli misin, üniversiteli misin?" diyorlar bunlara. Havalı olmak dikkat çekmek için böyle giyiniyorlar, ama aslında hiç de olmuyorlar. (O, 12 Yaş)

G5. Çocukların kıyafeti renkli falan olmalı, çünkü küçük çocuklar. Kafama silah dayasalar bile ben büyüklerin tarzında kıyafetleri giymem! (O, 11 Yaş)

G14. Çocuklar, Superman'li kıyafeterler giymeli... çocuk kıyafeti giymeli. ... Burda reklamdaki çocuk büyüdü, kendine tarz verdi ama büyükler gibi tarz verdi, ... bizim okulun müdürü hep kravat takar, siyah takım elbise giyer, gözlük takar bu çocukta öyle giyiniyordu onun büyükler gibi olması yanlış... (O, 10 Yaş)

Oğlan çocuklarının aksine kız çocukları, yetişkin tarzda kıyafetleri moda olarak algılamakta; beğenmekte ve giymek istemektedir.

G3. Ben büyük ablalar için yapılan kıyafetleri daha çok severim. Daha çok hoşuma gidiyor onların giydikleri, daha çok etkiliyor beni. (K, 12 Yaş)

G6. Ben omzu açık kıyafetler istiyorum, annem hiç beğenmiyor sen daha küçüksün diyor. Bana göre onlar daha güzel, prensesli falan olanlar çocuklar için, benim yaşım büyüdüğü için büyüklerin kıyafetlerini giymek istiyorum. Onları beğeniyorum. (K, 10 Yaş)

\section{Reklamdaki Tüketim Nesnelerine Yüklenen Anlamlar}

Reklamdaki çocukların yeni ve şık kıyafetler giymeleri, lüks evlerde görünmeleri araştırmaya katılan çocuklar için bir zenginlik göstergesidir. Bu noktada; 
çocukların, tüketim nesnelerini birer gösterge olarak anlamlandırmaya daha küçük yaşlarda başladıkları söylenebilir. Çocuklar, reklamcıların reklamı yapılan ürünü kullanmaları halinde insanların toplumda nasıl algılanacağına dair mesajlarının da farkındadır. Konuyla ilgili aşağıdaki ifadeler dikkat çekicidir:

G14. Çocuğun ailesi bence çok zenginler çocuktan anlıyorum zengin olduklarını; gözlüğünden, ayakkabısının yeniliğinden, evlerinin güzelliğinden zengin olduğunu anladım. Reklamı hazırlayanlar, "X Markası giyerseniz zengin görünürsünüz" diyor! ( $\mathrm{O}, 10$ Yaş)

G12. Reklamı yapanlar çocuklara "Bunları alırsanız daha tarz yaşamınız olur " diyorlar. "Arkadaş çevreniz çok olur" diyor. "Herkes size iyi bakar" diyor. (O, 11 Yaş)

G7. Bazı kıyafetler ilgi çekici ve havalı oluyor, biz de giyince dikkat çekici olabiliyoruz. Reklam da bunları giyersen öyle olursun diyor. (K, 11 Yaş)

Tüketim nesnelerine yüklenen anlamlar konusunda, oğlan çocuklarının daha fazla sorgulayıcı olduğu ve tüketim nesneleri ile toplumda ön plana çıkma, farklı ve üstün olma yargılarını reddetme tutumu içerisinde oldukları görülmektedir. Bu tespitle ilgili şağıdaki ifadeler dikkat çekicidir:

G1. Reklamdaki moda sözü, elbiseyle ilgi çekme doğru değil. Okulda bankta otururken böyle giyinmiş çocuğa Vauv! Diye bakmam ben. (O, 10 Yaş)

G12. Çocukların ne giydiği önemli değil, yakışanı giymeleri önemli. (O, 11 Yaş)

G2. Ben hiç özenmedim bu çocuğa, herkes kendi bulduğu kıyafeti giyer. Bu kıyafeti giyersem havalı olacam diye bir şey yok. (O, 8 Yaş)

Oğlan çocuklarının aksine kız çocukları, tüketim nesnelerinin insanlara saygınlık, gösteriş, üstünlük ve ön planda olma; kıskanılma özellikleri kazandırdığını düşünmektedir. Dahası, tüketim nesnelerini mutlulukla ilişkilendirmektedirler. Konuyla ilgili aşağıdaki ifadeler dikkat çekicidir:

G6. Bir arkadaşım reklamdakilerini giyse o çocuğun havalı olduğunu cool takıldığını düşünürdüm. X Markasını giyerseniz daha havalı daha cool olursunuz diyo reklam, bence doğru diyor. (K, 10 Yaş)

G3. Kıyafetiyle arkadaşlarının arasında ön plana çıkmış. Benim bir arkadaşımda böyle giyinse bizden daha ön planda olur. (K, 12 Yaş)

G9. Çocuk bence mutlu bir çocuk ve çok moda... (Tarz demek istiyor.) ... arkadaşları ona çok bakıyordu bi de çok kıskanıyordu. (bir hayranlık vardı bu esnada konuşmada) (K, 8 Yaş)

\section{Çocukların Gözünde Tüketim Tercihinde Ailelerin Rolü}

Alışveriş tercihinde anne babanın mı çocukların mı tercihinin önemli olduğu sorusuna oğlan çocuklarının "aile tercihleri" cevabını verirken, kız çocuklarının 
ağırlıklı olarak "kendi tercihleri" cevabını verdiği görülmektedir. Oğlan çocuklarının, alışveriş sırasında anne babayı doğru karar verici, yanlışlara müdahale edici güç olarak konumlandırdığı; kız çocuklarının ise benim tercihim, benim kararım yaklaşımı içerisinde olduğu görülmektedir. Bu tespitlere dair aşağıdaki ifadeler dikkat çekicidir:

G14. Ailemin tercihi önemli, pahalı mı ucuz mu onlar karar verir. $(\mathrm{O}$, 10 Yaş)

G1. Ailemin tercihleri önemli. Çoğunlukla onların seçtiğini giyerim. (O, 10 Yaş)

G11. Bazı çocuklar, çok renkli çok pahalı şeylere kaçıyor; ailelerin de karışması gerekir yırtıklı pırtıklı bir şey almak isterlerse aileler müdahele eder. $(\mathrm{O}, 12$ Yaş)

G3. Hem kendim hem ailemin kararları önemli, ama son kararı ben veririm. (K, 12 Yaş)

G10. Kendim alacaksam benim tercihlerim önemlidir. (K, 10 Yaş)

Ayrıca çocuklara, "Reklamda gördüğünüz bir şeyi aileniz almasaydı siz de hayal kırıklığı yaratır mıydı?" sorusu sorulmuş, çocukların ağırlıklı olarak "Hayır" yanıtını verdiği görülmüştür. Çocuklar isteklerine ailelerin olumsuz cevap vermesini olgunlukla karşılamakta, özellikle maddi koşulların farkında olduklarını, ailelerine saygı duyacaklarını belirtmektedir. Konuyla ilgili ifadeler şöyledir:

G6. Ailem almasaydı hayal kıııklığına uğramazdım, tutturmazdım almaları için çünkü; onların diyelim parası yoktur ondan saygı gösterirdim. (K, 10 Yaş)

G1. Reklamda beğenip de ailem almasaydı, bende hayal kırıklı̆ı yaratmazdı; çünkü annemle babam hayır diyorsa vardır bir bildikleri. Ne bileyim üzerimde güzel durmayacağını düşünmüş olabilirler, alsam bile hayalimdekinin o kıyafet olmayacağını düşünmüş olabilirler. Biliyorlardır yani... (O, 10 Yaş)

G14. Ailemin ilk masraflarını ödemesini sonra benim intiyaçlarımı almasını isterdim, reklamda beğendiğim bişeyi almazlarsa hiç üzülmezdim. (O, 10 Yaş)

\section{Sonuç}

Günümüz tüketim toplumu, Sillier tarafından oburluk çağı ismiyle adlandırılmaktadır (Sillier, 2010'dan akt. Asıl, 2016). Öyle ki bu çağda yanlızca yetişkin bireyler değil, çocuklar da birer hedef kitle olarak ele alınmaktadır. TV'de yayınlanan çocuk reklamlarına moda kavramı, tüketim nesnelerinin taşıdığı anlam göstergeleri, yetişkin tarzında ürünlerin çocuklar için yapılan ve onları birer yetişkin minyatür haline getiren halleri dâhil edilmektedir. Bu unsurlara yönelik, çocukların bakış açıarının ortaya çıkartılmaya çalışıldığı bu çalışmada kritik sonuçlara ulaşılmışır. 
Öncelikle çocukların moda kavramını "yeni, farklı, orjinal, lüks, herkesin istediği" gibi kavramlarla ilişkilendirdikleri görülmüştür. Çocuk modasının, yetişkinlerinkinden farklı; çocuk olma halleriyle uyumlu bir moda olması konusunda görüş belirtmişlerdir. Bu konuda oğlan çocuklarının kız çocuklardan daha bilinçli olduğu görülmüştür. Kız çocukları için moda ve dış görünüş oğlan çocukları için olduğundan daha fazla önemlidir. Bu durumun onların özel günlere ve arkadaş çevrelerindeki sosyal kabule daha fazla önem vermelerinden kaynaklandığı söylenebilir. Çocuklar ayrıca modayı belirleyen unsurların reklam ve sosyal medya ile bağlantılı olduğu yönünde bir farkındalığa da sahiptir.

Çocukların, reklamların amacına dair bir farkındalığa sahip oldukları görülmüştür. Onlara göre reklamlar, ürünleri tanıtmak, onlar hakkında bilgiler vermek, ürünleri sattırmak, insanların ilgisini çekmek gibi amaçlarla yapılmaktadır. Oğlan çocukları, reklama daha temkinli ve şüpheci yaklaşmakta; satın alma kararlarında reklamın daha az etkili olduğunu belirtmektedir. Kız çocuklarının ise reklamdaki ürün sayesinde ilgi çekici olacağına inandığı; bu yüzden reklamdaki ürünü satın alma eğilimi gösterdiği görülmektedir. Bu durum, Kirsh'in 8-12 yas aralığında, çocukların reklamı yapılan ürünleri satın alma eğilimi gösterdiği (Kirsh, 2010) görüşünü kız çocukları özelinde doğrulayan bir sonuç olmuştur.

Yetişkin tarzında üretilen kıyafetlerin reklamı konusunda, oğlan çocukları, çocukların çocuk gibi giyinmesi gerektiğini belirtmekte, yaş ve kıyafet uyumu konusunda daha bilinçli yargılar taşımaktadır. Buna karşın kız çocukları, yetişkin tarzda kıyafetleri moda kavramıyla ilişkilendirmekte, beğenmekte ve satın alma eğilimi göstermektedir. Başkalarının dikkatini çekecek, "tarz olan" kıyafetleri önemsediklerini vurgulamaktadırlar. Bu noktada, kız çocuklarının, dış görünüşe oğlan çocuklarından daha fazla önem verdiği; kıyafet gibi bir tüketim nesnesi ile arkadaş çevrelerinde yer edinme ve ön planan çıkma kaygısı taşıdığı söylenebilir. Bu sonuç; daha önce belirtilen, kız çocuklarının çekiciliğe ve arkadaşları arasında kabul edilmeye daha fazla önem verdiğine dair tespiti (Özbek, 2002'den akt Ateşoğlu ve Türkkahraman, 2009) destekler bir sonuç olarak görülebilir. Yine kız çocuklarının tüketim nesnesiyle arkadaşları çevresinde ön plana çıkacakları görüşüne sahip olmaları, Chin'in, 2001 yılında, kız çocuklarının tüketimle birlikte kendilerini daha güçlü hissettiklerini ortaya çıkardığı (Chin, 2001'den akt. Ellis, 2011) araştırma sonucunu da doğrular niteliktedir.

Çocuklar, reklamdaki tüketim nesnelerinin, aynı zamanda birer anlamlar göstergesi olduğunun farkındadır. Onlar için lüks evler, şık kıyafetler vb. zenginlik göstergesidir. Bu durum Williamson'ın (2001, s. 12), "insanların reklamlardaki ürünlerin başkaları için neler ifade ettiğiyle ilgilendiği" görüşünü çocuklar için de doğrulayan bir sonuç olmuştur. Aynı zamanda Elliott ve Leonard'ın (2004), çocukların markalı spor ayakkabı giyenleri zengin ve popüler olarak algıladıkları araştırma sonucu ile de uyum göstermektedir. Tüketim nesnelerine yüklenen anlamların kabulü noktasında, cinsiyete dayalı bir farklılık görülmüştür. Oğlan çocukları, tüketim nesnelerine anlamlar yüklenmesi konusunu daha reddedici ve sorgulayıcı 
bir tutumla ele almakta; çocuk söz konusu olunca, tüketim nesnelerinin ayrıcalık kazandırmayacağını savunmaktadır. Buna karşın, kız çocuklarının, tüketim nesnelerini mutlulukla ilişkilendirdikleri; kişilerin reklamda tarif edildiği gibi tüketim nesneleri ile saygın olma ve kıskanılma özelliklerini kazanacaklarına inandıkları görülmektedir. Bu yönüyle kız çocuklarının reklamlardan oğlan çocuklarından daha fazla etkilendikleri söylenebilir. Bu sonuç, daha önce oğlan çocuklarının kız çocuklarına nazaran reklamlardan ve televizyondan daha fazla etkilendiklerini belirten (Asıl, 2016) araştırmadan farkıı bir sonuç olarak karşımıza çıkmaktadır.

Alışveriş tercihinde, kız çocuklarının daha çok kendilerini ön plana çıkardığı, oğlan çocuklarının anne babayı ön plana çıkardığı görülmektedir. Kız çocuklarının bu durumu, Pilcher'in (2011), çocukların kıyafet söz konusu olduğunda kendi bilgi ve değerlendirmelerini ön planda tuttuklarını ortaya çıkaran araştırması ile uyumlu bir sonuç olarak ortaya çıkmıştır. Oğlan çocuklarının durumu ise Asıl'ın (2006, s. 164) çocuların "tüketim algılarını ve tüketici davranışlarını içinde bulundukları aile ve toplumun etkisiyle" oluşturduğu görüşüyle uyumlu bir sonuç olmuştur. Reklamda gördükleri bir ürünün satın alınmaması konusunda hayal kırıklığı yaşayıp yaşamadıkları noktasında, çocukların ailelerine saygı göstereceği, maddi koşulların farkında bir tutumla ailelerine saygı duyduğu görülmüştür. Bu sonuç, Tokgöz'ün (1979), Tüketirsen mutlu olursun mesajının pompalandığı bu dünyada, çocuklar ne kadar hayal kırıkığına uğramakta? Kendilerini koşullama eğilimi mi göstermekte yoksa kızgınlık durumuna mı geçmekte? sorusuna bir yanıt olarak algılanabilir. Bu sonuç ayrıca, çocuğun reklamı yapılan üründen mahrum bırakılması durumunda aile içi anlaşmazlıkların ortaya çıktığı ve çocuğun psikolojik gelişiminin olumsuz etkilendiği görüşü (Kuruoğlu, 1999'dan akt. Doğan, 2003) ile farklı bir sonuç olarak bulunmuştur.

Sonraki çalışmalar için araştırmanın farklı yaş grupları arasında yapılması, aile gelir durumu değişkeninin araştırmalara dâhil edilmesi ya da çocukların reklam ve tüketim nesnelerine yükledikleri anlamlara dair ailelerin deneyimlerine de yer verilmesi önerilebilir.

\section{Kaynakça}

Adorno, T. (2009). Kültür endüstrisi - Kültür yönetimi. (N. Ülner, M. Tüzel, E. Gen, Çev.). İstanbul: İletişim Yayınları.

Akpınar, T. (2015). Popüler kültür içerisinde çocukların tüketime yönlendirilme süreçleri. Yayınlanmamış doktora tezi, Marmara Üniversitesi.

Altunışık, R., Özdemir Ş., Torlak, Ö. (2006). Modern pazarlama. İstanbul: Değişim Yayınları.

Asıl, S. (2016). Çocukların Tüketim Algısının Resimlere Yansımaları. Journal of Research in Education and Society. 3(1), s. 164-185. Erişim 2 Mart 2019, https:// www.academia.edu/34485433/\%C3\%87ocuklar\%C4\%B1n_t\%C3\%BCketim_ 
alg \% C4\%B1s\%C4\%B1n\%C4\%B1n_resimlere_yans\%C4\%B1mas\%C4\%B1. pdf

Ateşoğlu, ì., Türkkahraman, M. (2009). Çocukların Tüketici Olarak Sosyalleşmesi. Süleyman Demirel Üniversitesi İktisadi ve İdari Bilimler Fakültesi Dergisi. 3(14), s. 215-228. Erişim 8 Mart 2019, https://dergipark.org.tr/download/article-file/194635

Baltacı, A. (2018). Nitel Araştırmalarda Örnekleme Yöntemleri ve Örnek Hacmi Sorunsalı Üzerine Kavramsal Bir İnceleme. BEÜ SBE Dergisi. 7(1), s. 231-274. Erişim 6 Nisan 2020, https://dergipark.org.tr/en/download/article-file/497090

Baudrillard, J. (2008). Tüketim toplumu. (H. Deliceçaylı, F. Keskin, Çev.). İstanbul: Ayrıntı Yayınları.

Barnard, M. (2002). Fashion as communication (Second Edition). Oxon: Routledge.

Berger, A. A. (2000). Ads, fads and consumer culture- Advertising's Impact on American character and socierty. USA: Rowman \& Littlefield Publishers.

Belk, R. (2017). Qualitative Reseacrh in Advertising. Journal of Advertising. 46(1), p. 36-47. Erişim 12 Mart 2019, https://www.tandfonline.com/doi/abs/10.1080/00 913367.2016.1201025?journalCode=ujoa20

Bocock, R. (1997). Tüketim. (I. Kutluk, Çev.). Ankara: Dost Kitabevi.

Chin, E. (2001). Purchasing power: Black kids and American consumer culture. Minneapolis: University of Minnesota Press.

Corsaro, W. (2005). The sociology of childhood. London: Pine Forge Press.

Crewe, L., Collins, P. (2006). Commodifying Children: Fashion, Space, and the Production of the Profitable Child. Environment and Planning. 38, p. 7-24. Erişim 6 Nisan 2020, https://www.researchgate.net/publication/23539601_Commodifying_Children_Fashion_Space_and_the_Production_of_the_Profitable_Child

Doğan, M. (2003). Televizyon reklamlarının çocuklar üzerindeki etkisi. Yayınlanmamış yüksek lisans tezi, Afyon Kocatepe Üniversitesi.

Elliott, R., Leonard, C. (2004). Exploring Fashion Brands and Consumption Symbolism Among Children of the 'British Poor'. Journal of Consumer Behaviour. 3(4), p. 347-359. Erişim 6 Nisan 2020, https://onlinelibrary.wiley.com/doi/abs/10.1002/ cb.147?casa_token=IHGwBejONLkAAAAA:x-GO4uwpGxwmX2-N5-HSZzLR1U1ha1Z4X7bsZdjLelbfwEfrbArOEhW7spihJQoyzeKEilz_tE1f-Kc

Ellis, L. (2011). Towards a contemporary sociology of children and consumption. Yayınlanmamış doktora tezi, Durham University.

Entwhistle, J., Wilson, E. (2001). Introduction: Bodydressing. J. Entwhistle ve E. Wilson, (Ed.), Body Dressing içinde (1-9). Oxford: Berg.

Ewen, S. (2001). Captains of consciousness- Advertising and the social roots of the consumer culture. NY: Basic Books. 
Feshbach, N., Dillman, A., Jordan, T. (1979). Children and Television Advertising: Some Research and Some Perspectives. Journal of Clinical Child Psychology. Bahar 1979, p. 26-30. Erişim 8 Mart 2019, http://eds.a.ebscohost.com/eds/ pdfviewer/pdfviewer?vid=4\&sid=86ce2207-375d-44e7-9390-d098ab3967d4\%40sessionmgr4006

Fox, A., Bacile, T., Nakhata, P. C., Weible, A. (2018). Selfie-Marketing Exploring Narcissism and Self-concept in Visual User-Generated Content on Social Media. Journal of Consumer Marketing. 35(1), p. 11-21. Erişim 8 Mart 2019, https:// www.emeraldinsight.com/doi/pdfplus/10.1108/JCM-03-2016-1752

Illich, I. (2011). Tüketim köleliği. (M. Karaşahan, Çev.). İstanbul: Pınar Yayınları.

Jacobson, L. (2008). Children and consumer culture in American society. Westport: Praeger Publishers.

Karaca, Y., Pekyaman, A., Güney, H. (2007). Ebeveynlerin Televizyon Reklam İçeriklerinin Çocuklar Üzerindeki Etkilerini Etik Açıdan Algılamalarına Yönelik Bir Araştırmaç Sosyal Bilimler Dergisi. IX (2), s. 231-250. Erişim 12 Mart 2019, http:// www.acarindex.com/dosyalar/makale/acarindex-1423867240.pdf

Kirsh, S. (2010). Media and youth: A developmental perspective. Malden: Wiley-Blackwell.

Koton. (2014). Tarzı Olan Çocuklar Reklam Filmi. Erişim 12 Mart 2020, https:// www.youtube.com/watch?v=w5mmdilyNFs

Kuruoğlu, H. (1999). Televizyon Reklamlarında Çocuk. İletişim Ortamlarında Çocuk Birey Sempozyumu Bildiriler El Kitabı, 13/15.

Lawlor, M., Prothero, A. (2008). Exploring Children's Understanding of Television Advertising - Beyond the Advertiser's Perspective. European Journal of Marketing. 42(11/12), p. 1203 - 1223. Erişim 12 Mart 2019, https://arrow.dit.ie/cgi/viewcontent.cgi?article $=1089 \&$ context $=$ buschmarart

McNeal, U. J. (1992). Kids as customers- A handbook of marketing to children. UK: Lexington Books

Moore-Shay, E. (1994). Kids' consumption: How children perceive the relationships between advertisements and products. Yayınlanmamış doktora tezi, University of Florida.

Morgan, D. L., Morgan, R. K. (2008). Single-case research methods for the behavioral and health sciences. Thousand Oaks, CA: SAGE Publications.

Odabaşı, Y. (1999). Tüketim kültürü. İstanbul: Sistem Yayıncılık.

Orçan, M. (2008). Osmanlı'dan günümüze modern Türk tüketim kültürü. Ankara: Harf Yayıncılık.

Özbek, T. (2002). 12-14 Yaş Adölesan Çağındaki Kız Çocukların Giysi Seçimi ve Modayla İlgilenme Durumları. Standard, 41 (483), 37-43. 
Pilcher, J. (2011). No Logo? Children's Consumption of Fashion. Childhood. 18(1), p. 128-141. Erişim 6 Nisan 2020, https://journals.sagepub.com/doi/ abs/10.1177/0907568210373668

Pole, C., Pilcher, J., Edwards, T., Boden, S. (2005). New Consumers? Children. Fashion and Consumption. Cultures of Consumption Research Programme Findings, 1-4. Erişim 6 Nisan 2020, http:// www.consume.bbk.ac.uk/researchfindings/newconsumers.pdf

Postman, N. (1982). 1982). The disappearance of childhood. New York: Delacorte Press.

Sağlam, D. (1990). Televizyon reklamlarının çocuklar üzerindeki etkileri. Yayınlanmamış yüksek lisans tezi, İstanbul Teknik Üniversitesi.

Sillier, Y. (2010). Oburluk çağı: Sıkıntıdan kaçarken, felsefe ve politik-psikoloji denemeleri. İstanbul: Yordam.

Tayfur, G. (1989). Televizyonun çocuklar üzerindeki etkisi. Yayınlanmamış yüksek lisans tezi, Marmara Üniversitesi.

Tokgöz, O. (1979). Televizyon Reklamları ve Çocuklar. II. Uluslararası Eğitim Teknolojisi Semineri. Erişim 12 Mart 2019, http://dergiler.ankara.edu.tr/dergiler/42/443/4972.pdf

Tokgöz, O. (1982). Televizyon reklamlarının anne-çocuk ikilisine etkileri. Ankara: A.Ü. S.B.F. Basın ve Yayın Yüksek Okulu Basımevi.

TÜiK (2017). İstatistiklerle Çocuk. Erişim 12 Mart 2019, http://www.tuik.gov.tr/ PreHaberBultenleri.do?id=27596

Türkoğlu, N. (2000). Gör-yorum: Gündelik yaşamda imgelerin gücü. İstanbul: Der Yayınları.

Weil, H. L. (2007). A good line of advertising: The historical development of children's advertising as reflected in St. Nicholas Magazine, 1873-1905. Yayınlanmamış doktora tezi, University of Missouri-Columbia.

Williamson, J. (2001). Reklamların dili: Reklamlarda anlam ve ideoloji. (A. Fethi, Çev.). Ankara: Ütopya Yayınevi.

Wisenblit, J., Priluck, R., Pirog, S. (2013). The Influence of Parental Styles on Children's Consumption. Journal of Consumer Marketing. 30(4), p. 320-327. Erişim 12 Mart 2019,

https://edisciplinas.usp.br/pluginfile.php/4076584/mod_resource/content/0/Survey_Anova_The\%20influence \%20of\%20parental\%20styles $\% 20$ on $\% 20$ childrens $\% 20$ consumption.pdf

Yıldııım, A., Şimşek, H. (2016). Sosyal bilimlerde nitel araştırma yöntemleri (10. baskı). Ankara: Seçkin Yayınları. 